\title{
Public health implications of rodent-borne zoonotic diseases
}

\author{
K Vrinda Menon ${ }^{\mathrm{a}}{ }^{\mathbb{D}}$ and Deepa Jolly ${ }^{\mathrm{b}}$
}

${ }^{a}$ Officer-in-charge, School of Zoonoses and Assistant Professor, Department of Veterinary Public Health, College of Veterinary and Animal Sciences, Mannuthy, Thrissur, Kerala Veterinary and Animal Sciences University, India

${ }^{\mathrm{b}}$ Assistant Professor, Department of Veterinary Public Health, College of Veterinary and Animal Sciences, Mannuthy, Thrissur, Kerala Veterinary and Animal Sciences University, India

Corresponding author: K Vrinda Menon | email: vrinda@kvasu.ac.in

Co-author: DJ: deepajolly@kvasu.ac.in

Received: 17-07-2020, Accepted: 12-08-2020, Published online: 21-09-2020

\begin{abstract}
Rodents are the most abundant and diversified order of living mammals in the world. Their proximity with human population helps in the transmission of various zoonotic diseases. They are known to transmit around 60 common zoonotic diseases and not only serve as reservoirs of some of the emerging zoonoses but also hosts for a number of infectious diseases. They also provide a nexus between wildlife and humans exposing humans to zoonotic diseases circulating in the natural ecosystem. Rodent populations fluctuate in abundance over both seasonal and multiannual time scales. Rodents are known to be the primary or definitive host for diseases like plague, leptospirosis, Lyme disease, tick-borne relapsing fever, hemorrhagic fever with renal syndrome, leishmaniasis, hymenolepiasis, and moniliformiasis; whereas in other diseases, rodents act as the secondary host. There is an urgent need for field studies of rodent population to determine the likely role of particular rodent species as reservoirs of these diseases and to understand rodent-human interactions.
\end{abstract}

Keywords: Rodents, Zoonotic diseases

\footnotetext{
doi: https://doi.org/10.51128/jfas.2020.A003 | How to cite this article: Menon, K V. and Jolly, D. 2020. Public health implications of rodent-borne zoonotic diseases. Journal of Food and Animal Sciences, 01(01): 13-21.

Copyright: Menon and Jolly, 2020. Open Access. This article is distributed under the terms of the Creative Commons Attribution 4.0 International License (http://creativecommons.org/licenses/by/4.0/), which permits unrestricted use, distribution, and reproduction in any medium, provided you give appropriate credit to the original author(s) and the source, provide a link to the Creative Commons license, and indicate if changes were made. The Creative Commons Public Domain Dedication waiver (http://creativecommons.org/publicdomain/zero/1.0/) applies to the data made available in this article, unless otherwise stated.
} 


\section{Introduction}

During the past decade there has been an increasing trend of diseases associated with smallmammal reservoirs. Among the mammals, rodents are the most abundant and diversified order of living mammals representing about $43 \%$ of the total number of mammalian species (Huchon et al., 2002). They usually live in close proximity with human population, their farm animals and pets. They also provide a nexus between wildlife and humans exposing humans to zoonotic diseases circulating in the natural ecosystem. The impact of rodents to agriculture crops is tremendous which leads to field damage, reduced yield of staple crops and vegetables and also affecting stored crops. Rapid development of industry and agriculture, together with climate change throughout the globe, has led to a change or increase in the occurrence of rodent-borne diseases. Rodents are known to transmit around 60 common zoonotic diseases and not only serve as reservoirs of some of the emerging zoonoses but also hosts for a number of infectious diseases (e.g., plague, salmonellosis, leptospirosis, leishmaniasis and viral hemorrhagic fevers) and play an important role in their transmission and spreading. They also cause damage to property leading to great economic burden to the society. The black rat (Rattus rattus), Norway rat (Rattus norvegicus), Asian house rat, (Rattus tanezumi) and Pacific rat (Rattus exulans) like the house mice (Mus musculus), have dramatically expanded their geographic range as a consequence of human activities (Aplin et al. 2011). All of these Rattus species originated in Asia, and can be found in sympatry due to their synanthropic behavior (McFarlane et al. 2012). These rodents have been implicated in the emergence and spread of diseases.

Public Health Biological characteristics of rodents enabling them to transmit diseases to animals and humans are cited below

- Climb wires and pipe both horizontally and vertically

- Gain entrance through spaces of $0.25 \mathrm{~cm}^{2}$

- Jump one feet from a horizontal surface

- Withstand falls from $50 \mathrm{ft}$ without being injured

- Swim as far as $0.8 \mathrm{~km}$ in open waters

- Burrow vertically in earth to a depth of $4 \mathrm{ft}$

- Pass through holes the size of a dime

- Run up almost any vertical surface

- Survive in between and underside of freezers

- Reproduce at 3 months with a litter size of 7-8 pups (20 pups/ yr)

- Weak bladder and urinate often

- Gnawing with sharp incisor teeth

\section{Factors affecting rodent population}

Weather conditions affect rodent population, especially, warm wet winters and springs increase rodent populations. Under climate change scenarios, rodent populations tend to increase in temperate zones, causing more interaction between human beings and rodents, leading to a higher risk of disease transmission. Breakdown in sanitation and inadequate hygiene are contributing factors to rat infestations in some European countries (Tassinari et al., 2008).

\section{Transmission of diseases to humans (Fig. 1)}

Rodent borne diseases can be transmitted via two different routes Meerburg et al., 2009)

a) Direct through biting, rodent faeces contaminated food/water and urine contaminated surface waters

b) Indirect through arthropods and livestock to humans

\section{Diseases directly transmitted to humans include}

- Hantavirus Pulmonary Syndrome

- Hemorrhagic Fever with Renal Syndrome

- Lassa Fever

- Leptospirosis

- Lymphocytic Choriomeningitis Virus (LCMV)

- Omsk Hemorrhagic Fever

- Plague

- Rat-Bite Fever

- Salmonellosis

- Campylobacteriosis

- Tularemia

- Parasitic diseases -Toxoplasmosis

Diseases indirectly transmitted include:

- Babesiosis

- California Serogroup Viruses

- Colorado Tick Fever

- Cutaneous Leishmaniasis

- Human Granulocytic

- Anaplasmosis

- Lyme Disease

- Murine Typhus

- Omsk Hemorrhagic Fever

- Powassan Encephalitis

- Scrub Typhus

- Rickettsial pox

- Relapsing Fever

- Rocky Mountain Spotted Fever

- Sylvatic Typhus

- Western Equine Encephalitis 
Menon and Jolly, 2020; https://doi.org/10.51128/jfas.2020.A003

Table 1-list of rodent-borne diseases associated with humans

\begin{tabular}{|c|c|c|}
\hline & $\begin{array}{c}\text { Disease } \\
\end{array}$ & Causative agent \\
\hline \multirow{19}{*}{$\begin{array}{l}\text { Bacterial } \\
\text { Diseases }\end{array}$} & $\begin{array}{l}\text { Boutonneuse or Mediterranean spotted } \\
\text { fever }\end{array}$ & Rickettsia conorii \\
\hline & Campylobacteriosis & Campylobacter spp. \\
\hline & Corynebacteriosis & Non-diphtheritic corynebacterium \\
\hline & Escherichia coli enteritis & Escherichia coli \\
\hline & Human granulocytic anaplasmosis & Anaplasma phagocytophilum \\
\hline & Leptospirosis & Leptospira spp. (Spirochates) \\
\hline & Listeriosis & Listeria spp. \\
\hline & Lyme disease & Spirochaetes \\
\hline & Murine typhus & Rickettsia typhi \\
\hline & Pasteurellosis & Pasteurella spp. \\
\hline & Plague & Yersenia pestis \\
\hline & Q Fever & Coxiella burnetti \\
\hline & Rat-bite fever, Haverhill fever & Spirillum minus, Streptobacillus moniliformis \\
\hline & Rickettsialpox & Rickettsia akari \\
\hline & Rocky Mountain spotted fever & Rickettsia rickettsi \\
\hline & Salmonellosis & Salmonella spp. \\
\hline & Scrub Typhus & Rickettsia tsutsugamushi \\
\hline & Sylvatic typhus & Rickettsia prowazekii \\
\hline & Tularaemia & Francisella tulerensis \\
\hline \multirow{22}{*}{$\begin{array}{l}\text { Viral } \\
\text { Diseases }\end{array}$} & Apoi virus disease & Apoi virus \\
\hline & Argentine hemorrhagic fever & Junin virus \\
\hline & Bolivian hemorrhagic fever & Machupo virus \\
\hline & Borna disease & Borna virus \\
\hline & Brazilian hemorrhagic fever & Sabia virus \\
\hline & Colorado tick fever & Coltivirus \\
\hline & Cowpox & Cowpox virus \\
\hline & Crimean congo haemorrhagic fever & Nairo virus \\
\hline & Hepatitis E & Hepatitis E virus \\
\hline & HFRS & Hanta virus \\
\hline & Kyasanur Forest Disease & Kyasanur Forest disease virus \\
\hline & Lassa fever & Lassa virus \\
\hline & Lujo hemorrhagic fever & Lujo virus \\
\hline & Lymphocytic choriomeningitis & Lymphocytic choriomeningitis virus \\
\hline & Omsk hemorrhagic fever & Omsk hemorrhagic fever virus \\
\hline & Powassan encephalitis & Powassan virus \\
\hline & Rabies & Rabies virus \\
\hline & Rift Valley fever & Rift Valley fever virus \\
\hline & Tick-borne encephalitis & Tick-borne encephalitis virus \\
\hline & Venezuelan Equine Encephalitis & Venezuelan equine encephalitis virus \\
\hline & Venezuelan hemorrhagic fever & Guanarito virus \\
\hline & Western Equine Encephalitis & Western equine encephalitis virus \\
\hline
\end{tabular}




\begin{tabular}{|l|l|l|}
\hline \multirow{5}{*}{} & Alariasis & Alaria spp. \\
\cline { 2 - 3 } & Amoebic dysentry & Entamoeba histolytica \\
\cline { 2 - 3 } & Angiostrongylosis & $\begin{array}{l}\text { Angiostrongylus cantonensis, Angiostrongylus } \\
\text { costaricensis }\end{array}$ \\
\cline { 2 - 3 } & Babesiosis & Babesia spp. \\
\cline { 2 - 3 } & Baylisascariasis & Baylisascaris procyonis \\
\cline { 2 - 3 } & Brachylaimiasis & Brachylaimidae \\
\cline { 2 - 3 } & Chagas & Trypanosoma cruzi \\
\cline { 2 - 3 } & Cryptosporidiosis & Cryptosporidium spp. \\
\cline { 2 - 3 } & Echinococcosis & Echinococcus spp. \\
\cline { 2 - 3 } & Echinostomiasis & Echinostoma \\
\cline { 2 - 3 } & Giardiasis & Giardia spp. \\
\cline { 2 - 3 } & Leishmaniasis & Leishmania spp. \\
\cline { 2 - 3 } & Neosporosis & Neospora caninum \\
\cline { 2 - 3 } & Schistsomiasis & Schistosoma spp. \\
\cline { 2 - 3 } & Taeniasis & Taenia spp. \\
\cline { 2 - 3 } & Toxascariasis & Toxascaris leonine \\
\cline { 2 - 3 } & Toxoplasmosis & Toxoplasma gondii \\
\cline { 2 - 3 } & Trichinosis & Trichinella spiralis \\
\hline
\end{tabular}

Figure 1. Transmission of diseases to humans

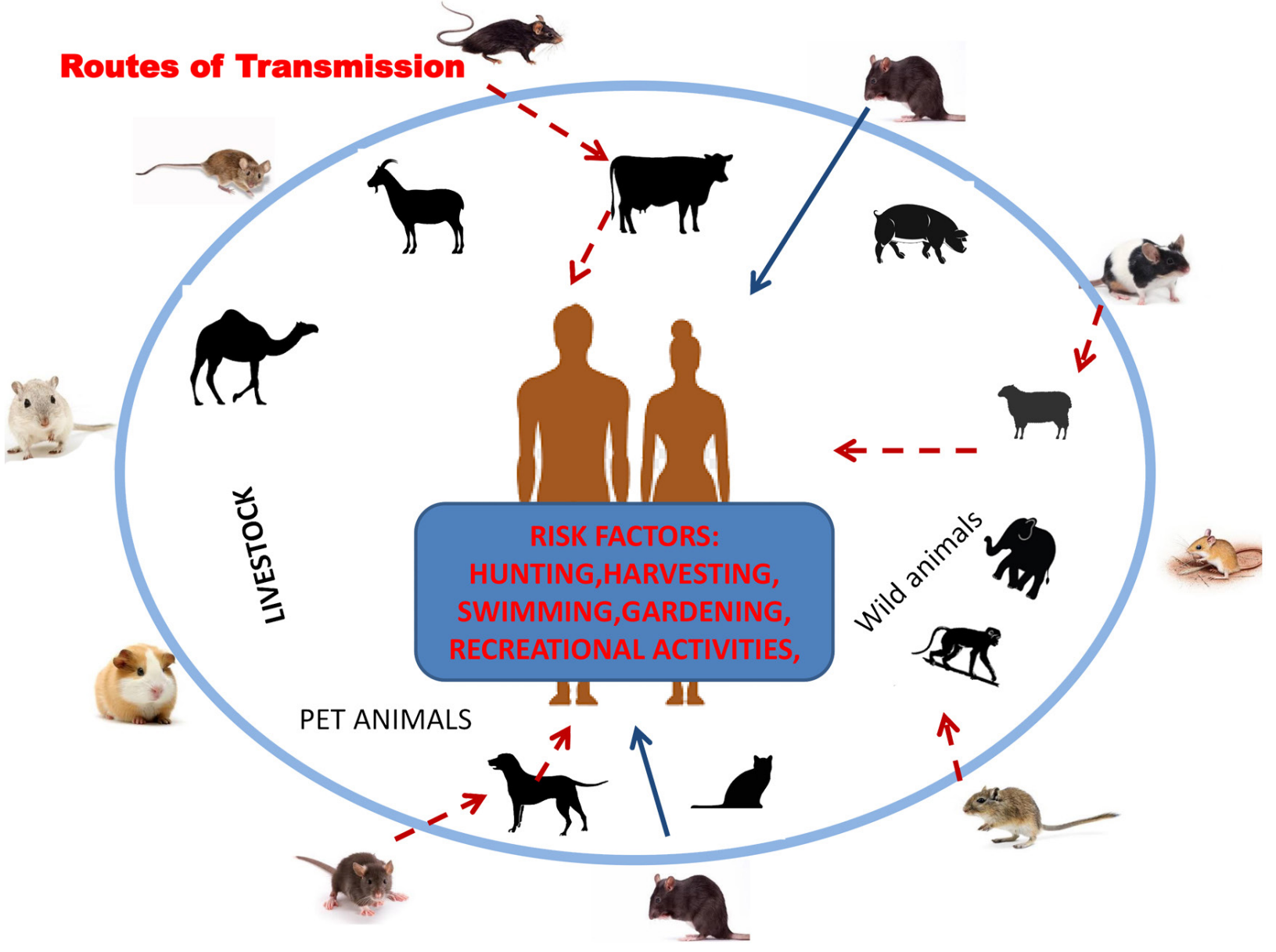




\section{Transmission of diseases to humans:}

Rodents are known to be the primary or definitive host for diseases like plague, leptospirosis, Lyme disease, tick-borne relapsing fever, hemorrhagic fever with renal syndrome, leishmaniasis, hymenolepiasis, and moniliformiasis; whereas in other diseases, rodents act as the secondary host. Diseases like plague, bartonellosis, Lyme disease, tularemia, tick-borne relapsing fever, Q fever, CrimeanCongo hemorrhagic fever, leishmaniasis, babesiosis, schistosomiasis, and fasciolosis are not only rodentborne but also are vector-borne diseases, while all the other diseases are only rodent-borne ( Rabiee et al., 2018). A few of the diseases are described below:

\section{Viral diseases}

\section{Hanta virus pulmonary syndrome:}

It was first recognised in 1993 in southwestern USA. Humans act as accidental hosts to this infection. The disease transmission is through aerosols generated from contaminated urine, feces and saliva of infected rodent. The seroprevalence in rodents in USA has been reported to be $17 \%$. The risk groups include Public Health workers, farmers, rodent trappers and military personnel (Jonsson et al. 2008; Zeits et al. 1997). Deer mouse is the primary reservoir of this infection. Disease in humans depends on Hantavirus species and can be classified as

\section{- Hemorrhagic Fever with Renal Syndrome (HFRS) \\ - Hantavirus Pulmonary Syndrome (HPS)}

The climate change has influenced the emergence of the disease in south-western USA due to drought which increased the pine nuts and grasshoppers which nourishes the deer mouse which are the main reservoirs of the disease. Moreover, subsequent floods led to rats coming out of burrows and having more contact with humans (Epstein 1995; Kolivras and Comrie 2004). The seropositivity of hantavirus Thottapalayam virus strain in the general population was reported to be about $4 \%$ by researchers from Christian medical college Vellore.

\section{Crimean Congo Haemorrhagic Fever}

It is caused by Nairovirus and is a tick-borne infection (Hyolomma). The risk groups include agriculture workers. Rodents host immature stages of ticks and conserve the pathogen. The case-fatality rate for the disease is reported to be 3-30\% (Ergonul 2006). The symptoms in humans include fever, myalgia, backache, photophobia, sharp mood-swings. Vaccines are available against the disease. Ribavirin is the drug of choice. Use of acaricides are essential to control ticks and reduce the incidence of the disease.

\section{Omsk Haemorrhagic Fever}

It is caused by Flavivirus and is a tick-borne infection which is endemic in Siberia (Holbrook et al. 2005). The virus is maintained in nature through circulation among ticks and rodents. The main symptoms of the disease include haemorrhagic fever and no encephalitis (Lin et al. 2003). The case-fatality rate is $0.5-3 \%$ ( $\mathrm{Li}$ et al. 2004).

\section{Kyasannur Forest Disease}

Flavivirus is the etiological agent for the disease and was first reported in 1955 in Shimoga, Karnataka. Rats host ticks and ticks transmit the disease to animals, mainly monkeys and humans. The risk groups of the disease include hunters, herders, forest workers, and farmers. The main symptom includes haemorrhagic fever and CFR is 2-10\% (Gould and Solomon, 2008). The seasonality of the infection is that, it mainly occurs in dry season, from November through June. It has been reported in Wayanad district of Kerala since 2013 and also recent reports in Goa in 2015. Vaccine is available against the disease and is used in endemic areas. Two vaccine doses at least one month apart to persons 7-65 years of age is administered. Booster dose of vaccine is recommended within 6-9 months after primary vaccination. Annual booster doses are recommended for 5 years after the last confirmed case in the area.

\section{Bacterial diseases}

\section{Plague}

The most famous disease associated with rodent presence is probably plague. The etiologic agent of the disease is Yersinia pestis. It caused a great havoc during its first ( $6^{\text {th }}$ and $\left.7^{\text {th }} \mathrm{AD}\right)$, second $\left(14^{\text {th }}\right.$ and $17^{\text {th }}$ AD) and third (19 ${ }^{\text {th }}$ and $20^{\text {th }}$ AD) pandemics (Perry and Fetherston, 1997). In India, it was last reported in Surat in 1994 (Ganapati 1995). It is a flea-transmitted disease and the disease is maintained in the sylvatic and urban cycle by the rodents as shown in the figure 2 .

Rodents are the true natural hosts of Y.pestis. At least 220 species of rodents in both temperate and tropical climate are known to be infected with plague bacillus. Tatera indica among the wild rodents and R.norvegicus and R.rattus among the commensal rodents are found to play an important role as reservoir of $Y$. pestis. Ecological studies point to a multiplicity of factors concerned in the fluctuating balance that exists between rodents of greater and lesser degree of susceptibility to the plague bacillus and in the degree of risk to which man is exposed.The main types of disease in humans include: 
1. Bubonic Plague: Symptoms include enlarged tender lymph nodes, fever, chills and prostration.

2. Septicaemic Plague: Symptoms include fever, chills, prostration, abdominal pain, shock and bleeding into skin and other organs.

3. Pneumonic Plague: Symptoms include fever, chills, cough and difficulty breathing; rapid shock and death, if not treated early .

4. Pharyngeal and Meningitic Plague: also documented

The organism is sensitive to most commonly available antibiotics. Proper waste disposal and rodent control can prevent the disease occurrence in humans.

Figure 2. Plague- sylvatic and urban cycle by the rodents

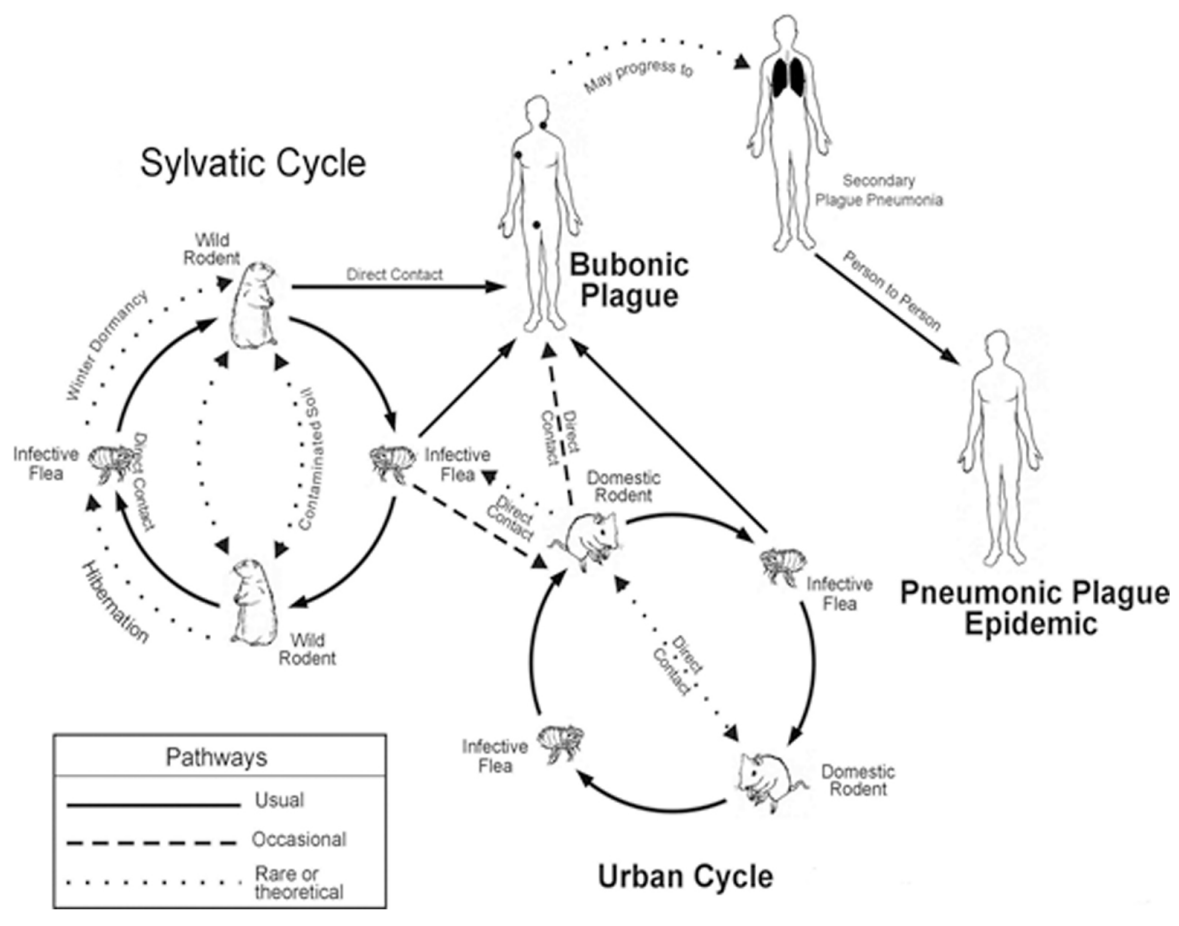

Table-2. Seroprevalence of Leptospira in different species of Rats in India

\begin{tabular}{|c|c|c|c|}
\hline S.No. & Species of Rats & Seroprevalence (\%) & Reference \\
\hline \multirow{6}{*}{1.} & \multirow{6}{*}{ Rattus rattus } & $37.0 \%$ & Koteeswaran (2006) \\
\hline & & $5.1 \%$ & Kuriakose et al. (2008) \\
\hline & & $0 \%$ & Patil et al. (2014) \\
\hline & & $58.3 \%$ & Priya et al. (2007) \\
\hline & & $7.1 \%$ & Sharma et al. (2003) \\
\hline & & $51.4 \%$ & Natarajaseenivasan et al. (2011) \\
\hline \multirow{4}{*}{2.} & \multirow{4}{*}{ Rattus norvegicus } & $39.1 \%$ & Parveen et al. (2016) \\
\hline & & $0 \%$ & Patil et al. (2014) \\
\hline & & $51.4 \%$ & Vedhagiri et al. (2010) \\
\hline & & $17.77 \%$ & Neethu (2015) \\
\hline \multirow{4}{*}{3.} & \multirow{4}{*}{$\begin{array}{l}\text { Unknown/other } \\
\text { Rattus species }\end{array}$} & $40.0 \%(24 / 60)$ & Bojiraj et al. (2017) \\
\hline & & $\begin{array}{l}\text { RH: } 22.3 \% \text { (183/819); RRf: } 19.7 \% \\
\text { (81/412) }\end{array}$ & Gangadhar et al. (2000) \\
\hline & & $8.8 \%(11 / 125)$ & Lahiri (1941) \\
\hline & & $52.1 \%(12 / 23)$ & Natarajaseenivasan et al. (2002) \\
\hline
\end{tabular}




\section{Leptospirosis}

It is caused by $L$. interrogans serovar Canicola, Icterrohaeemorrhagia, Gripotyphosa, Hardjo, Pomona Tarassovi. The two species Rattus. norvegicus and Rattus. rattus have become ubiquitous in urban environments and are significant sources of many zoonotic pathogens especially leptospirosis. Rodents are infected for life and act as carriers of a particular serovar prevailing in the area. Rodents have an enormous ability to excrete large number of leptospirae in the urine, which is the main source of contamination incriminating human and animal leptospirosis. In India it is Rattus rattus that has been found reservoir for several serovars. The organism is transmitted through infected urine of animals to humans. It can survive in urine and is excreted for long durations in different animals including rodents.

$$
\begin{aligned}
& \text { Dogs - } 700 \text { days } \\
& \text { Pigs - upto one year during it's life time } \\
& \text { Rodents - life time } \\
& \text { Cattle - } 120 \text { to } 700 \text { days }
\end{aligned}
$$

The seroprevalence of Leptospira in different species of rats in India as observed by different research workers is as cited in the table no. 2

The incubation period of the disease is $1-2$ weeks in humans and occurs in two forms:

\section{Icteric form}

Sudden onset with general symptoms, hepatomegaly with jaundice, renal-oliguria, anuria, azoturia, electrolyte imbalance, myocarditis \& meningitis

\section{Anicteric form}

Benign Symptoms

\section{Parasitic diseases}

\section{Angiostrongyliasis}

It is known as rat lungworm. The disease affects the brain and spinal cord. It is caused by a parasitic nematode (roundworm) called Angiostrongylus cantonensis. The adult form of $A$. cantonensis is only found in rodents. Snails, slugs, freshwater shrimp, land crabs, and frogs can become infected by ingesting this larvae. Humans can become infected with $A$. cantonensis if they eat raw or undercooked infected intermediate host (Spratt, 2005). Meningitis (eosinophilic meningitis) is also observed in some instances. Some infected people don't have any symptoms or only have mild symptoms like severe headache and stiffness of the neck, tingling or painful feelings in the skin or extremities, low-grade fever, nausea, and vomiting. Sometimes, a temporary paralysis of the face may also be present, as well as light sensitivity. When preparing food for cooking, any suspect food products should be boiled for at least 3-5 minutes, or frozen at $5^{\circ} \mathrm{F}\left(15^{\circ} \mathrm{C}\right)$ for at least 24 hours; this will kill the larval stage of the worm.

\section{Toxoplasmosis}

It is caused by Toxoplasma gondii, a protozoan parasite. The infection in humans is through ingestion of cyst-containing meat (carnivores) or ingestion of oocysts (environmental contamination) and raw goat's milk as well as congenital infection, transfusion (rare), lambing and transplantation. Cats are definitive hosts and rats are the main prey which harbour infection and transmit through faeces to livestock and humans. Consumption of rodents by pigs can infect the animal and infection is transmitted to humans by consumption of pork (Meerburg, 2006; Kijlstra et al., 2008). The infective stages of the parasite are: tachyzoites, tissue cysts, bradyzoites and oocysts. The organism causes abortions in pregnant women and congenital anomalies in fetuses. Cutaneous lesions of toxoplasmosis in humans has also been reported.

\section{Rickettsial diseases}

\section{Scrub typhus}

It is a vector borne disease first described in Japan in 1889. It is caused by Orientia tsutsugamushi. The pathogen is transmitted by bite of trombiculid mites that are hosted by various rodent species such as Norway rat, bandicoot rat, housemouse and striped field mouse. Symptoms in humans include fever, headache, muscle-pain and gastrointestinal symptoms. More virulent strains can cause haemorrhages and intravascular coagulation (Varghese et al., 2006). It is prevalent in India and is commonly reported in Kerala and often confused with leptospirosis and dengue fever. The organism is sensitive to Doxycycline.

\section{Murine typhus}

Rodents more specifically rats are associated with the worldwide distribution of Rickettsia typhi. It is transmitted by rat flea. The main symptoms observed in humans include headache, fever, nausea and body aches. It is a rarely observed disease in India. Rashes on arms and legs are also observed in humans infected with the disease. It persists in endemic areas where rat population remains high (Azad, 1990).

\section{Control and Prevention Measures}


Prevention strategies include educating people particularly those at most risk of infection, limiting contact with rodents, use of personal protective equipment (boots, gloves, masks, etc.), washing hands with soap and water regularly following close contact with rodents and avoiding insect bites is necessary in the prevention of these diseases. Ensuring rodentproof doors, sealed holes and detailed/cleaned floors in shadowy, hard-to-reach spots. Rodents tend to favor nesting and reproducing and being most active in often hard-to-reach (and thus often prone to being skipped over during service visits). Employing any of the electronic remote sensors available on the market could help as important food safety and public health monitors. Cleaning up any excrement and associated rodent filth together with cleaning and disinfection $\mathrm{s}$ also required (Corrigan, 2019). Vaccines have not been approved for the prevention of most of these diseases. Most prevention and control programs use Integrated Pest Management (IPM) concepts in their rodent control efforts (Brown and Laco, 2015).

\section{Conclusion}

Rodents play a significant role in transmission of a large number of diseases to humans. There is a need for models that characterise demographic and population density changes of rodents with climate, its effect on their dispersal rates and pattern and the effects on the abundance of vectors and pathogens. There is an urgent need for field studies of rodent population to determine the likely role of particular rodent species as reservoirs of these diseases and to understand rodent-human interactions.

"That which can be foreseen can be prevented." Will Mayo, 1910

\section{Authorship contribution statement}

Vrinda Menon: Conceptualization, Writing - original draft, Writing - review \& editing, Deepa Jolly: Writing - review \& editing.

\section{Acknowledgments}

All the authors acknowledge and thank their respective Institutes and Universities.

\section{Funding}

This compilation is a review article written by its authors and required no substantial funding to be stated.

\section{Declaration of Competing Interest}

All authors declare that there exist no commercial or financial relationships that could, in any way, lead to a potential conflict of interest.

\section{References}

Azad, A.F. 1990. Epidemiology of Murine Typhus. Annual Review Entomol. 35(1), 553.

Aplin K, Suzuki H, Chinen AA, Chesser RT, et al. Multiple geographic origins of commensalism and complex dispersal history of Black Rats. PLoS ONE 2011;6:e26357.

Bonnefoy X, Kampen H, Sweeney K. Public health significance of urban pests. 2008. World Health Organisation. http://www.euro.who.int/data/ assets/pdf file/0011/98426/E91435.pdf.

Brown L.M. and Laco J. 2015. Rodent Control and Public Health: A Description of Local Rodent Control Programs. J. Environ. Health. 78(4):2829.

Corrigan B. 2019. Public Health Importance of Urban Rodents. Annual Rodent Control Issue - Cover Story

Epstein, P.R. 1995. Emerging diseases and ecosystem instability: new threats to public health. $\mathrm{Am} \mathrm{J}$ Public Health. 85(2), 168

Ergonul, O. 2006. Crimean-Congo haemorrhagic fever. The Lancet Infectious Dis. 6(4), 203.

Huchon D., Madsen O., Sibbald MJ.J.B., Ament K., Stanhope M.J., Catzeflis F., De Jong W.W. and Douzery E.J.P. 2002. Rodent phylogeny and a Timescale for the Evolution of Glires: Evidence from an Extensive Taxon Sampling using Three Nuclear Genes. Mol .Biol. Evol. 19, 1053.

Ganapati, MB, India's pneumonic plague outbreak continues to baffle. 1995. British Med. J. 311(7007), 706.

Gould E.A. and Solomon T. 2008. Pathogenic flaviviruses. The Lancet. 371(9611), 500.

Holbrook M.R., Aronson J.F., Campbell G.A., Jones S., Feldmann H. and Barrett A.D.T. 2005. An animal model for the tickborne flavivirus Omsk hemorrhagic fever virus. J Infectious Dis. 191(1), 100 .

Jonsson C.B., Hooper J. and Mertz G. 2008. Treatment of hantavirus pulmonary syndrome. Antiviral Res. 78(1) 162.

Kijlstra A., Meerburg B., Cornelissen J., De Craeye S., Vereijken P. and Jongert E. 2008. The role of rodents and shrews in the transmission of Toxoplasma gondii to pigs, Vet. Parasitol. 156(3-4), 183.

Kolivras K.N. and Comrie N.C. 2004. Climate and infectious disease in the southwestern United 
States. Progress in Physical Geography. 28(3), 387.

Kuo CC, Wang HC, Huang CL. The potential effect of exotic Pacific rats Rattus exulans on vectors of scrub typhus. J Appl Ecol. 2011;48:192-198.

Li L., Rollin P.E., Nichol S.T., Shope R.E., Barrett A.D.T. and Holbrook M.R. 2004. Molecular determinants of antigenicity of two subtypes of the tick-borne flavivirus Omsk haemorrhagic fever virus. J Gen Virol. 85(6), 1619

Lin D., Li L., Dick D., Shope R.E., Feldmann H., Barrett A.D.T. and Holbrook M.R. 2003. Analysis of the complete genome of the tick-borne flavivirus Omsk hemorrhagic fever virus. Virology. 313(1), 81.

McFarlane R, Sleigh A, McMichael T. 2002. Synanthropy of wild mammals as a determinant of emerging infectious diseases in the AsianAustralasian region. Eco Health. 9:24-35.

Meerburg B.G. 2006. Zoonotic Risks of Rodents in Livestock Production, Vol PhD, Wageningen, University of Amsterdam, 176

Meerburg B., Singleton G. and Kijlstra A. 2009. Rodent-borne diseases and their risks for public health. Critical reviews microbiol. 35. 221-70. 10.1080/10408410902989837.
Perry R.D. and Fetherston J.D. 1997. Yersinia pestisetiologic agent of plague. Clin Microbiol Rev. 10(1), 35.

Rabiee M.H., Mahmoudi A., Siahsarvie R., Kryštufek B., Mostafavi E. 2018. Rodent-borne diseases and their public health importance in Iran. PLoS Negl Trop Dis. 12(4):e0006256. Published 2018 Apr 19. doi:10.1371/journal.pntd.0006256

Spratt D.M. 2005. Australian ecosystems, capricious food chains and parasitic consequences for people.Int J Parasitol. 35(2005), 717.

Tassinari W.S., Pellegrini D.C., Sá C.B., Reis R.B., Ko A.I. and Carvalho M.S. 2008. Detection and modelling of case clusters for urban leptospirosis. Trop. Med. Int. Health. 13:503-12.

Varghese G.M., Abraham O.C., Mathai D., Thomas K., Aaron R., Kavitha M.L. and Mathai E. 2006. Scrub typhus among hospitalised patients with febrile illness in South India: magnitude and clinical predictors. J Infection. 52(1), 56.

Zeits P.S., Graber J.M., Voorhees R.A., Kioski C., Shands L.A., Ksiazek T.G., Jenison S. and Khabbaz R.F. 1997. Assessment of Occupational Risk for Hantavirus Infection in Arizona and New Mexico. J Occup Environ Med. 39(5), 463. 